\title{
Role of the Oxide Support on the Structural and Chemical Evolution of Fe Catalysts during the Hydrogenation of $\mathrm{CO}_{2}$
}

Mauricio Lopez Luna, ${ }^{1}$ Janis Timoshenko, ${ }^{1}$ David Kordus, ${ }^{1}$ Clara Rettenmaier, ${ }^{1}$ See Wee Chee, ${ }^{1}$ Adam S. Hoffman, ${ }^{2}$ Simon R. Bare, ${ }^{2}$ Shamil Shaikhutdinov, ${ }^{1, *}$ Beatriz Roldan Cuenya ${ }^{1}$

${ }^{1}$ Department of Interface Science, Fritz Haber Institute of the Max Planck Society, 14195 Berlin ${ }^{2}$ SSRL, SLAC National Accelerator Laboratory, Menlo Park, California 94025, USA.
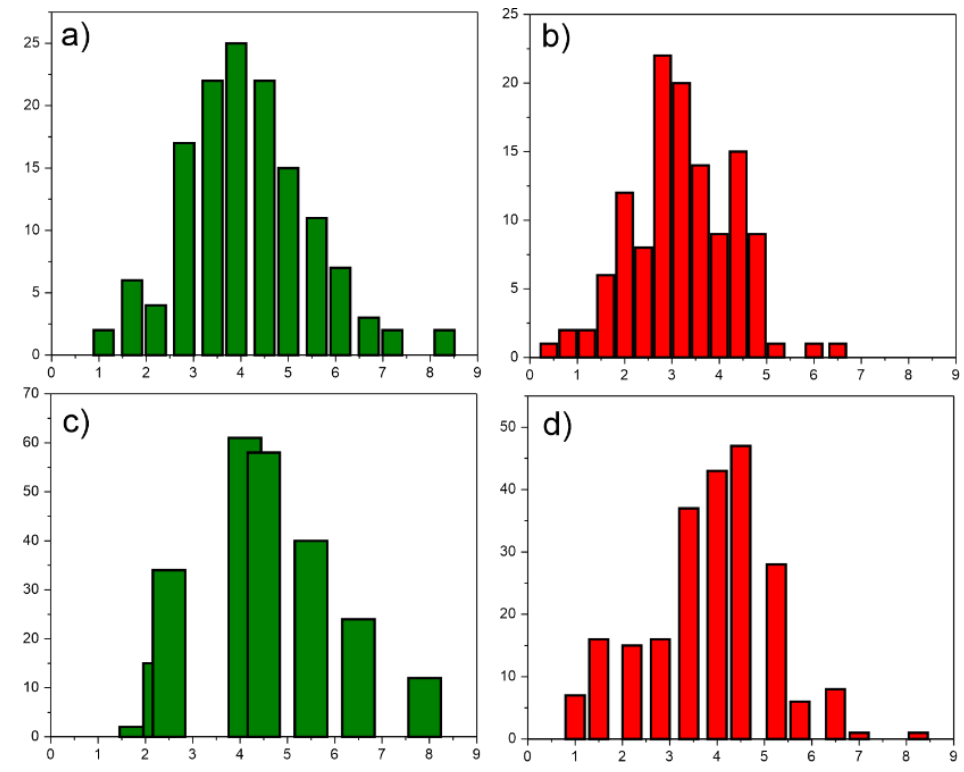

Figure S1. Height histograms obtained from the analysis of AFM images of iron NPs prepared by inverse micelle encapsulation and deposited onto $\mathrm{SiO}_{2} / \mathrm{Si}(001)$ before (a) and after (b) NAPXPS measurements. The results for the NPs on an $\mathrm{Al}_{2} \mathrm{O}_{3}(0001)$ substrate are shown in (c) and (d), respectively. The corresponding images are shown in Figure 1 of the main text. 

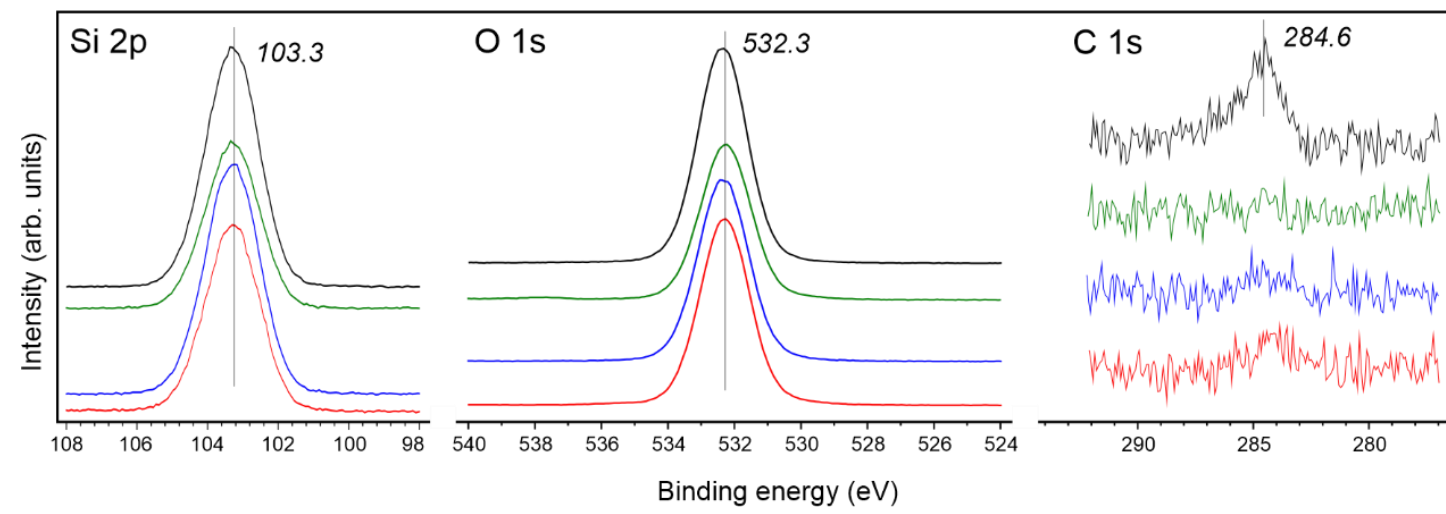

Figure S2. Si 2p, O 1s, and C 1s NAP-XPS spectra of micellar Fe NPs deposited onto a $\mathrm{SiO}_{2} / \mathrm{Si}(001)$ substrate. The spectra are aligned using the Si $2 \mathrm{p}$ peak set to $103.3 \mathrm{eV}$.

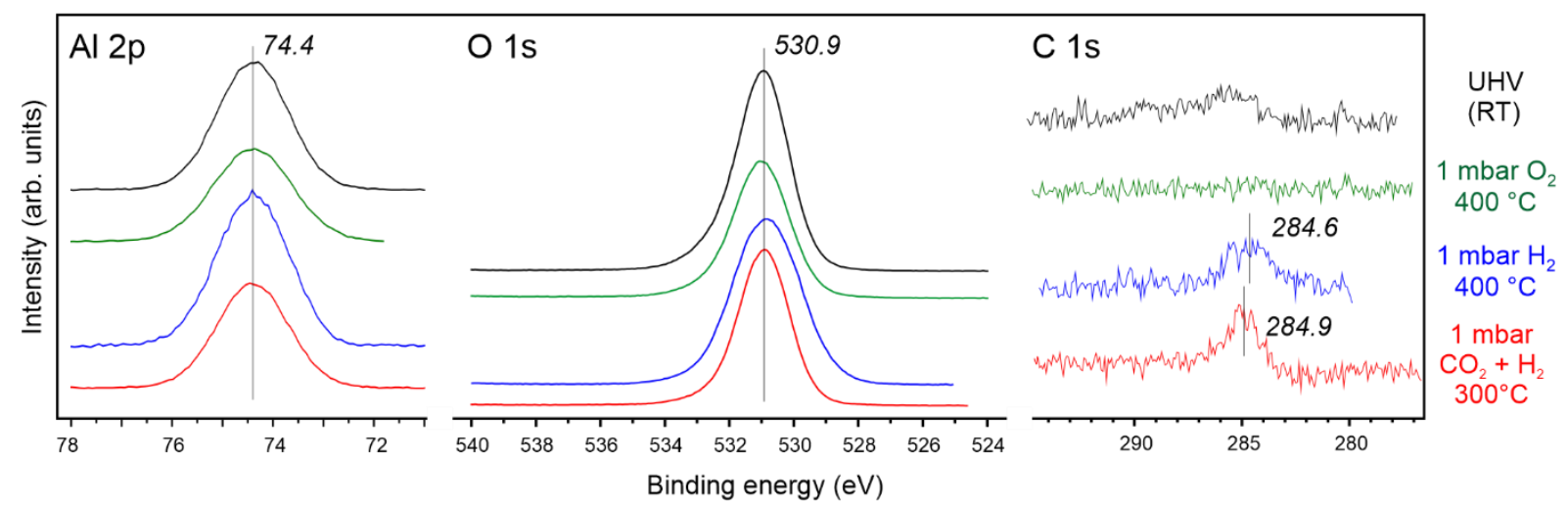

Figure S3. Al 2p, O 1s, and C 1s NAP-XPS spectra of micellar Fe NPs deposited onto an $\mathrm{Al}_{2} \mathrm{O}_{3}(0001)$ substrate. The spectra are aligned using the $\mathrm{Al} 2 \mathrm{p}$ peak set to $74.4 \mathrm{eV}$. 


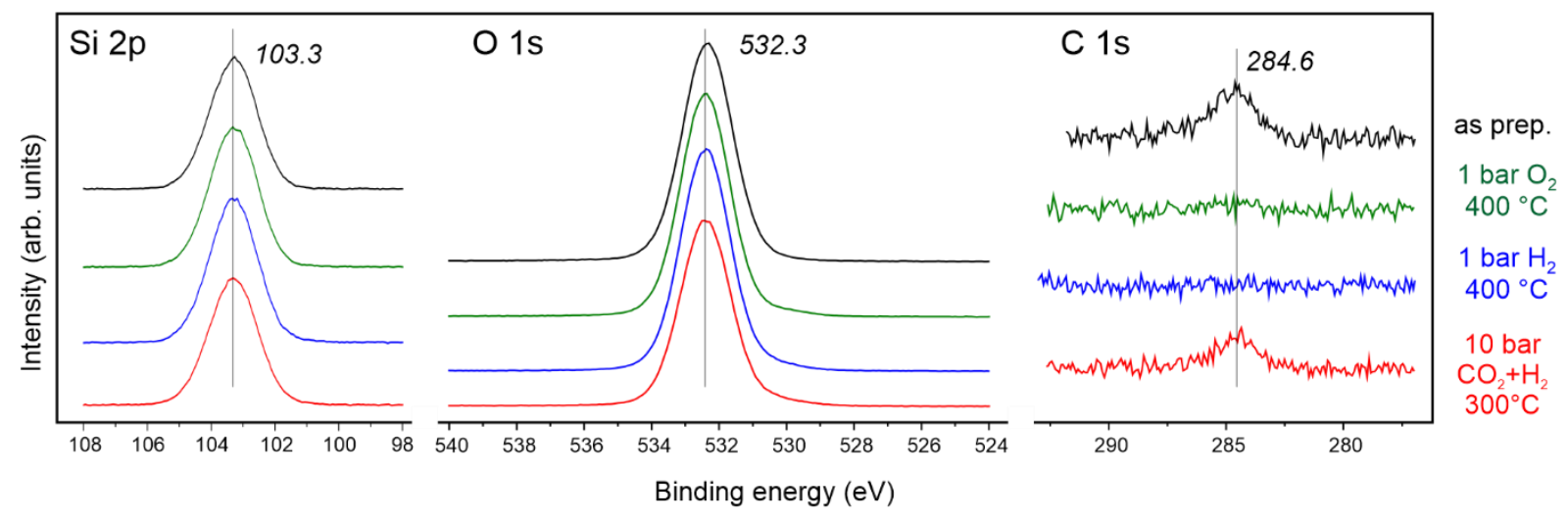

Figure S4. Si 2p, O 1s, and C 1s XPS spectra all measured in UHV at room temperature on "as prepared" micellar Fe NPs on a $\mathrm{SiO}_{2} / \mathrm{Si}(001)$ substrate and after high pressure treatments as indicated.

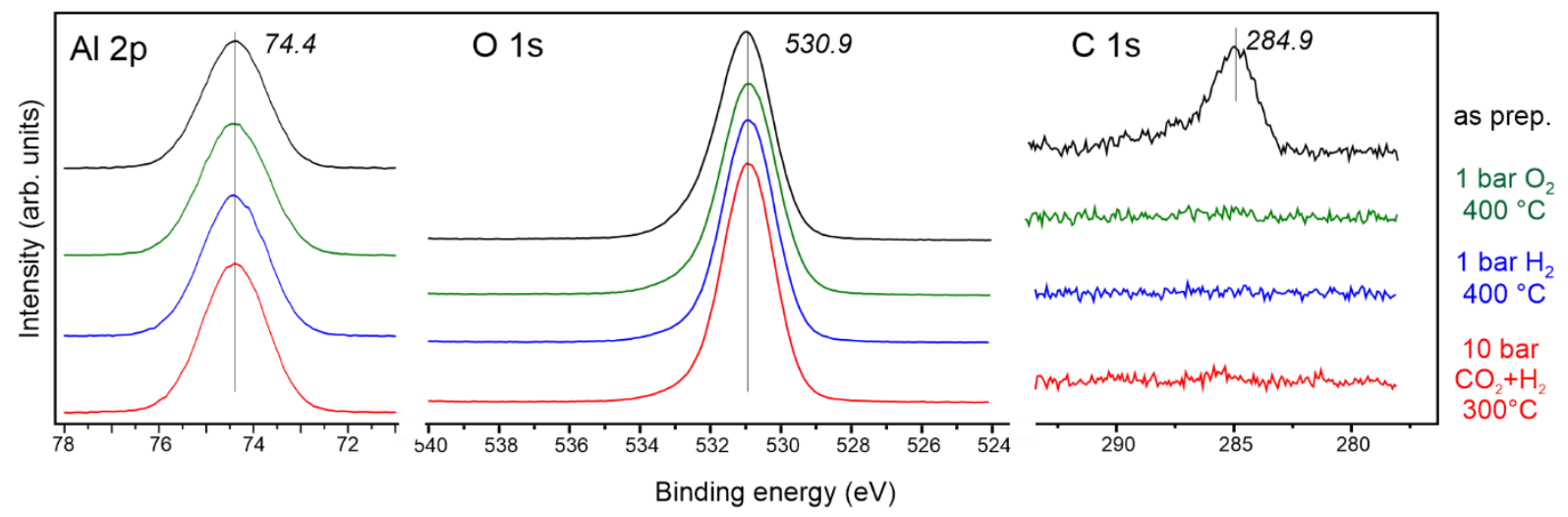

Figure S5. Al 2p, O 1s, and C 1s XPS spectra measured in UHV at room temperature on "as prepared" micellar Fe NPs on an $\mathrm{Al}_{2} \mathrm{O}_{3}(0001)$ substrate and after high pressure treatments as indicated. 


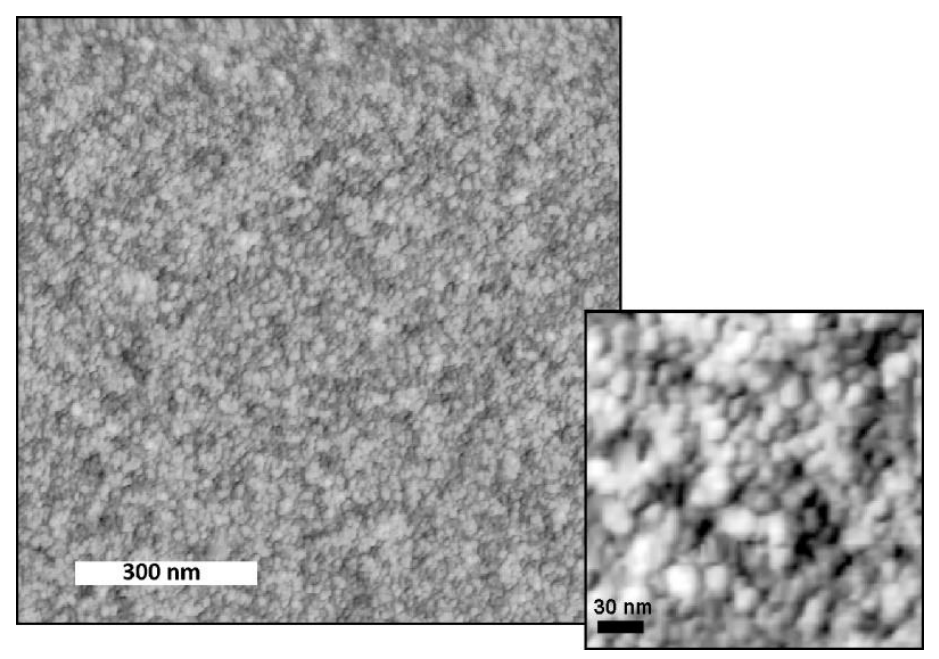

Figure S6. Typical AFM image of the Fe NPs deposited by PVD onto $\mathrm{SiO}_{2} / \mathrm{Si}(111)$.
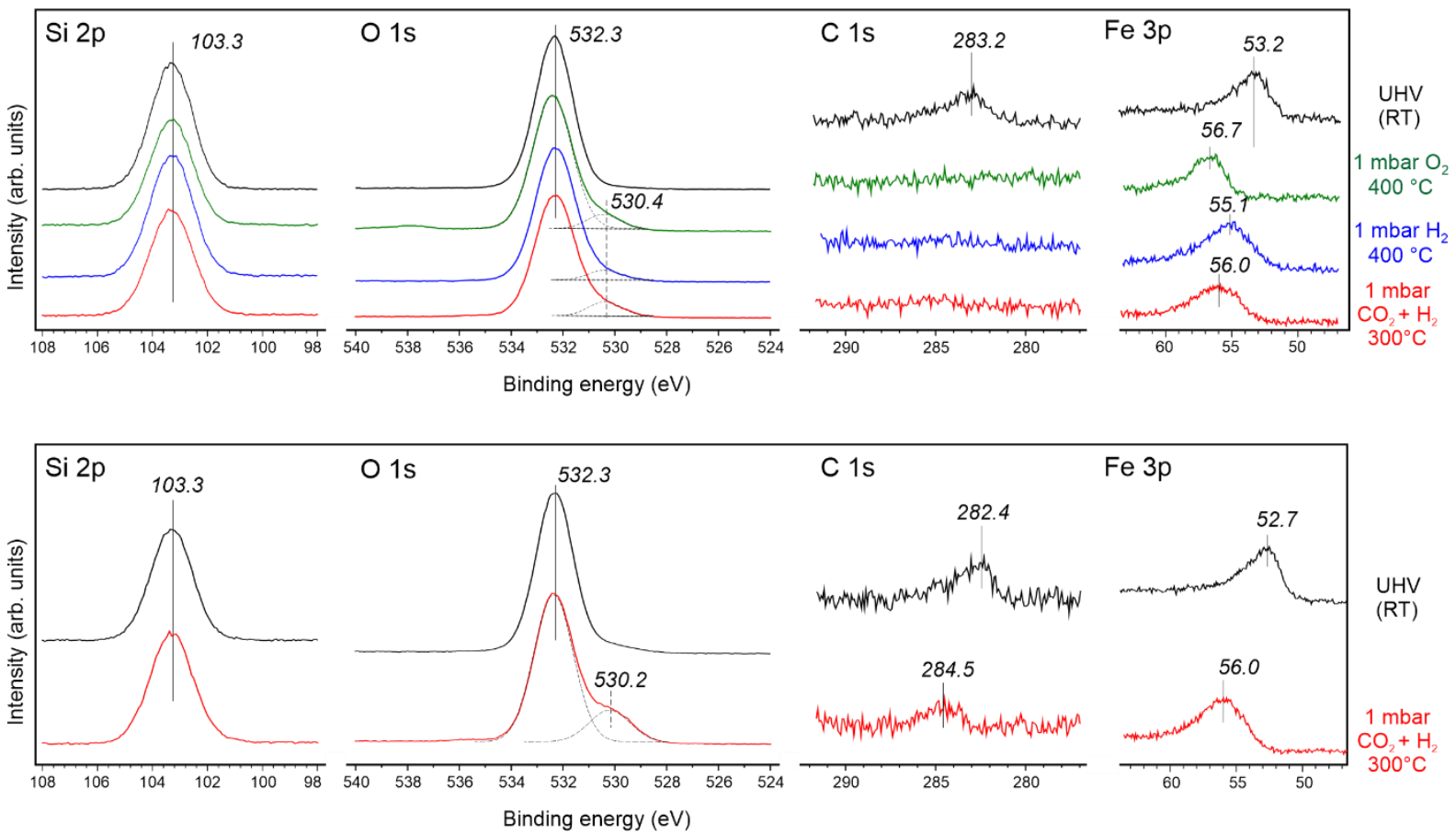

Figure S7. Si 2p, O 1s, C 1s, and Fe 3p NAP XPS spectra of Fe NPs deposited by PVD onto a $\mathrm{SiO}_{2} / \mathrm{Si}(001)$ substrate. The spectra are aligned using the $\mathrm{Si} 2 \mathrm{p}$ peak. 

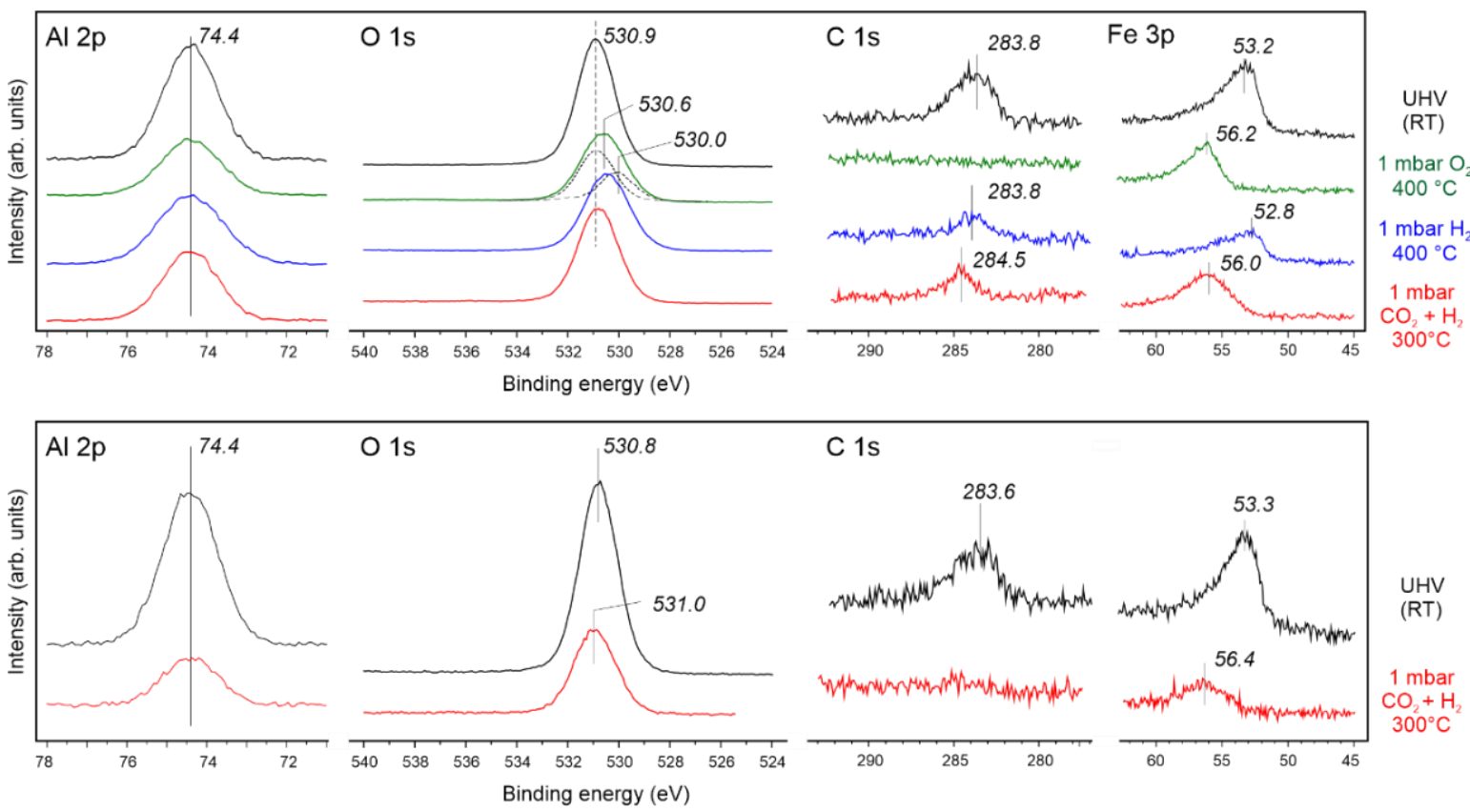

Figure S8. Al 2p, O 1s, C 1s, and Fe 3p NAP XPS spectra of Fe NPs deposited by PVD onto a $\mathrm{Al}_{2} \mathrm{O}_{3}(0001)$ substrate. The spectra are aligned using the $\mathrm{Al} 2 \mathrm{p}$ peak.

Due to the higher density of Fe NPs in the PVD-prepared samples (see Figure S6) as compared to micellar samples, it was possible to detect the oxidation of Fe NPs via changes in the $01 \mathrm{~s}$ region which is dominated by the $\mathrm{O} 1 \mathrm{~s}$ signal from the oxide supports. For the $\mathrm{SiO}_{2}$-supported NPs (Figure S7), a prominent shoulder appears at $530.4 \mathrm{eV}$ which is assigned to $\mathrm{O}$ in the iron oxide phase. The latter is more difficult to see on the $\mathrm{Al}_{2} \mathrm{O}_{3}$-supported system (Figure S8) because of strong overlapping with the $\mathrm{O}$ signal of alumina peaked at $530.9 \mathrm{eV}$. It is clear, however, that the signal becomes considerably broader in $\mathrm{O}_{2}$ with a maximum shifted to $530.6 \mathrm{eV}$ due to another $\mathrm{O}$ state centered at $530.0 \mathrm{eV}$ associated with the iron oxide. 


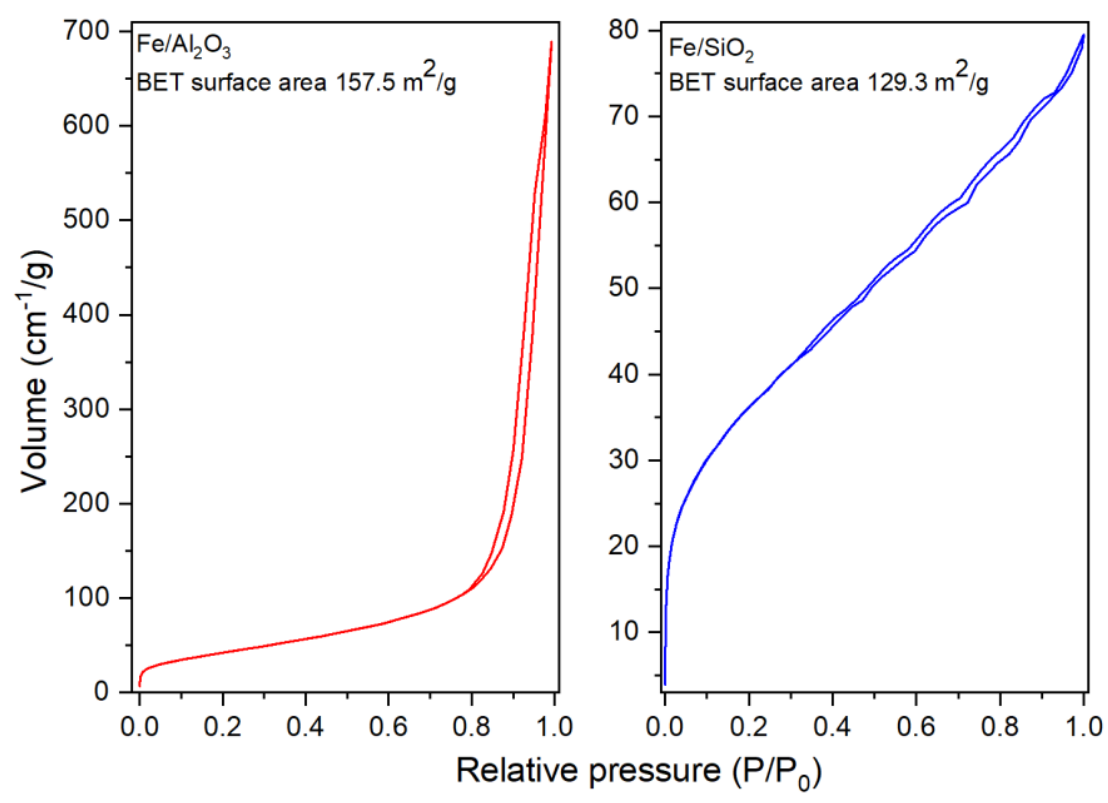

Figure S9. $\mathrm{N}_{2}$ adsorption isotherms obtained on the $\mathrm{Fe} / \mathrm{Al}_{2} \mathrm{O}_{3}$ and $\mathrm{Fe} / \mathrm{SiO} \mathrm{O}_{2}$ nanocrystalline powder catalysts. The measured BET surface areas are indicated.
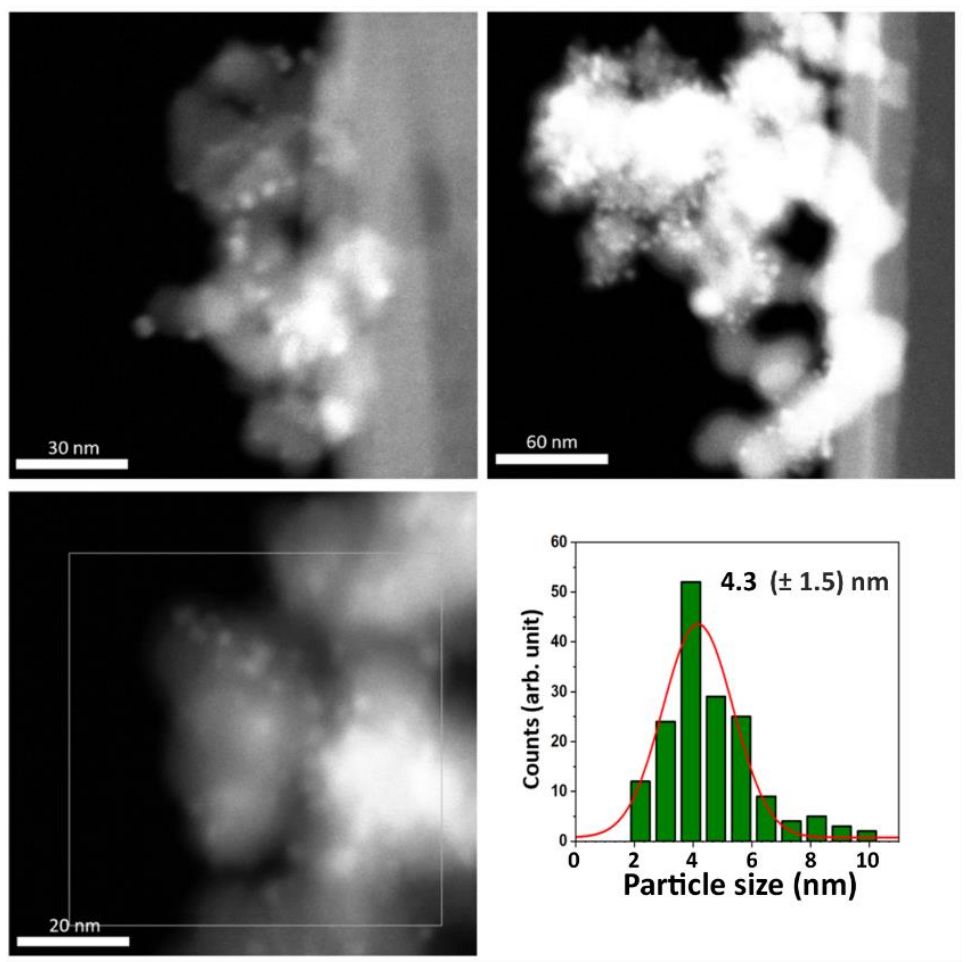

Figure S10. STEM-HAADF images and particle size distribution in the $\mathrm{Fe} / \mathrm{SiO}_{2}$ catalysts prepared by impregnation with the Fe micellar precursor and subsequent calcination in oxygen at $400^{\circ} \mathrm{C}$. 

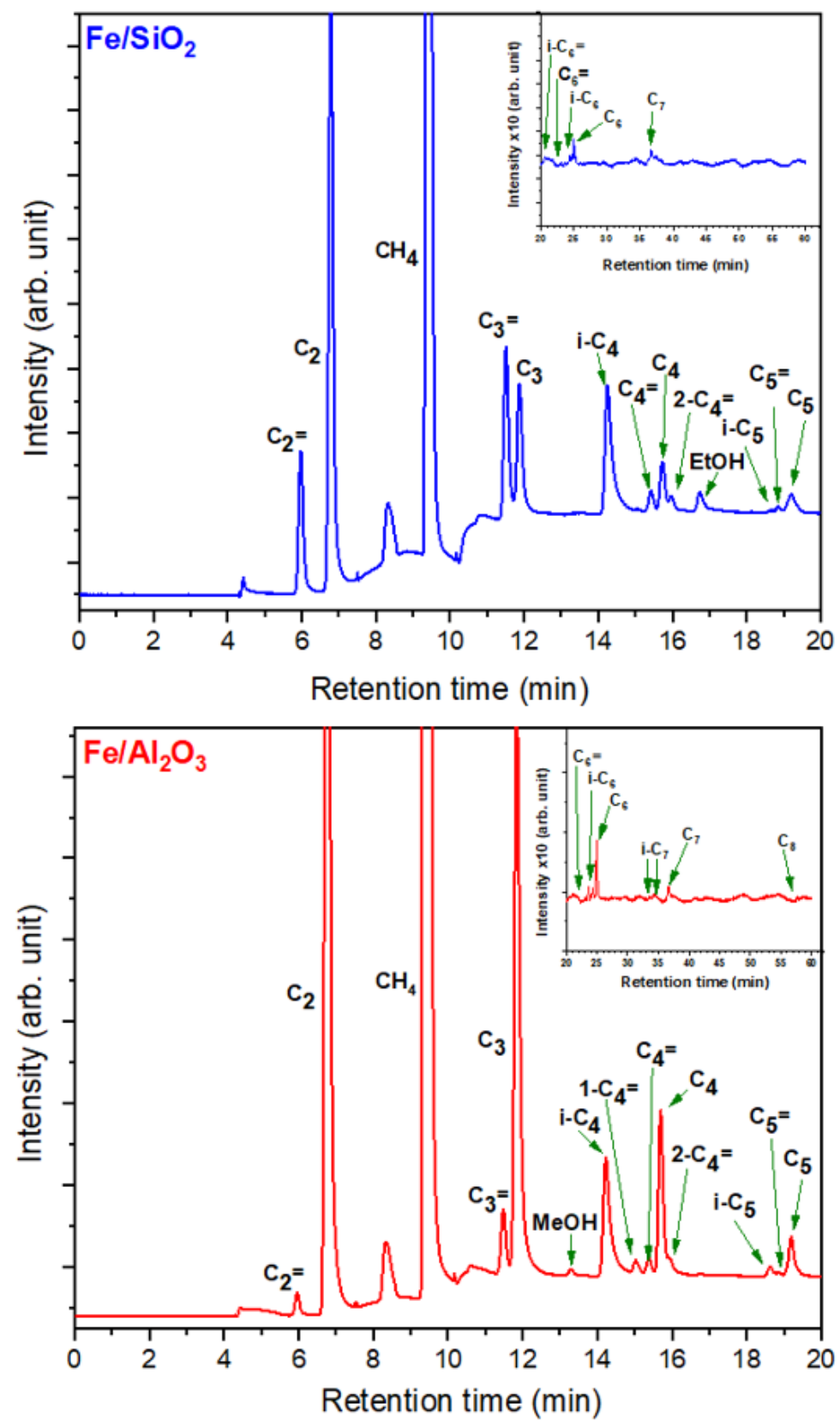

Figure S11. Gas chromatograph spectra of the $\mathrm{Fe} / \mathrm{SiO}_{2}$ and $\mathrm{Fe} / \mathrm{Al}_{2} \mathrm{O}_{3}$ nanocrystalline powder catalysts during the $\mathrm{CO}_{2}$ hydrogenation at steady state. The $\mathrm{C}_{\mathrm{n}}$ products are identified based on the mass-spectra of the corresponding peaks, see Figure S12. 

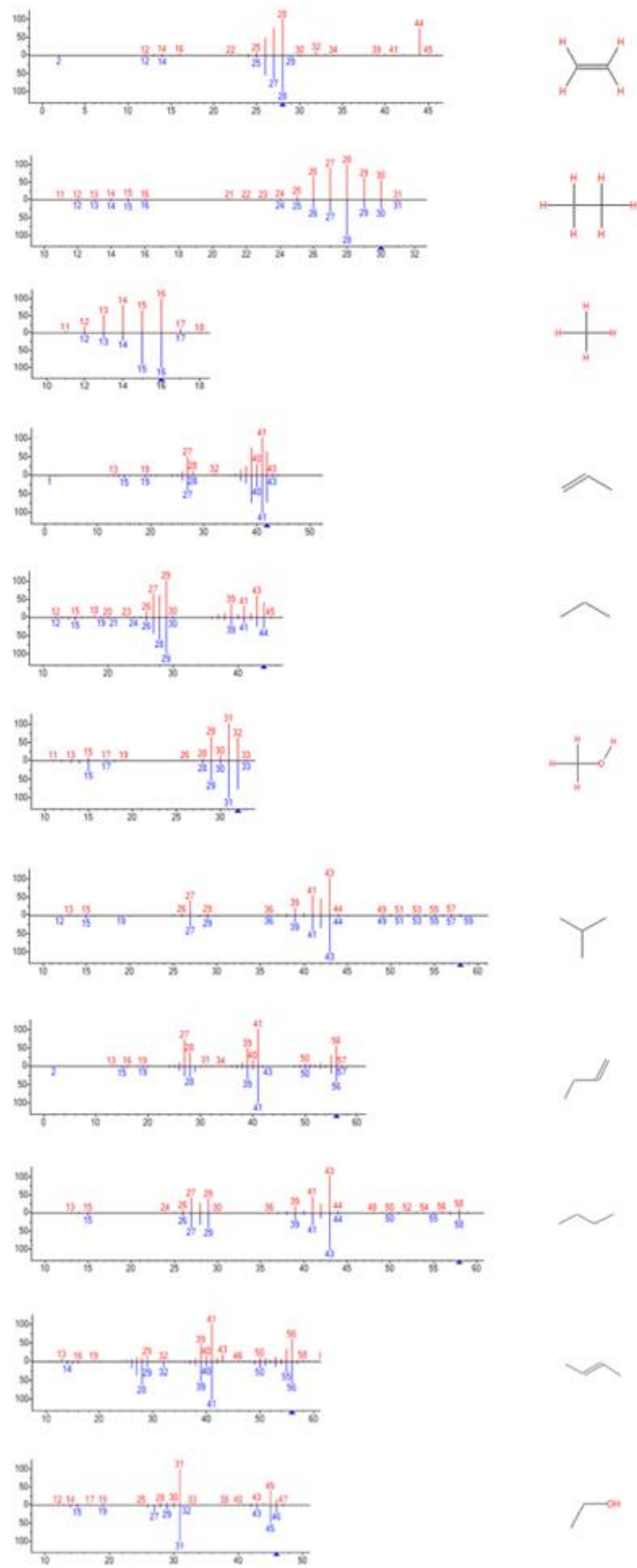

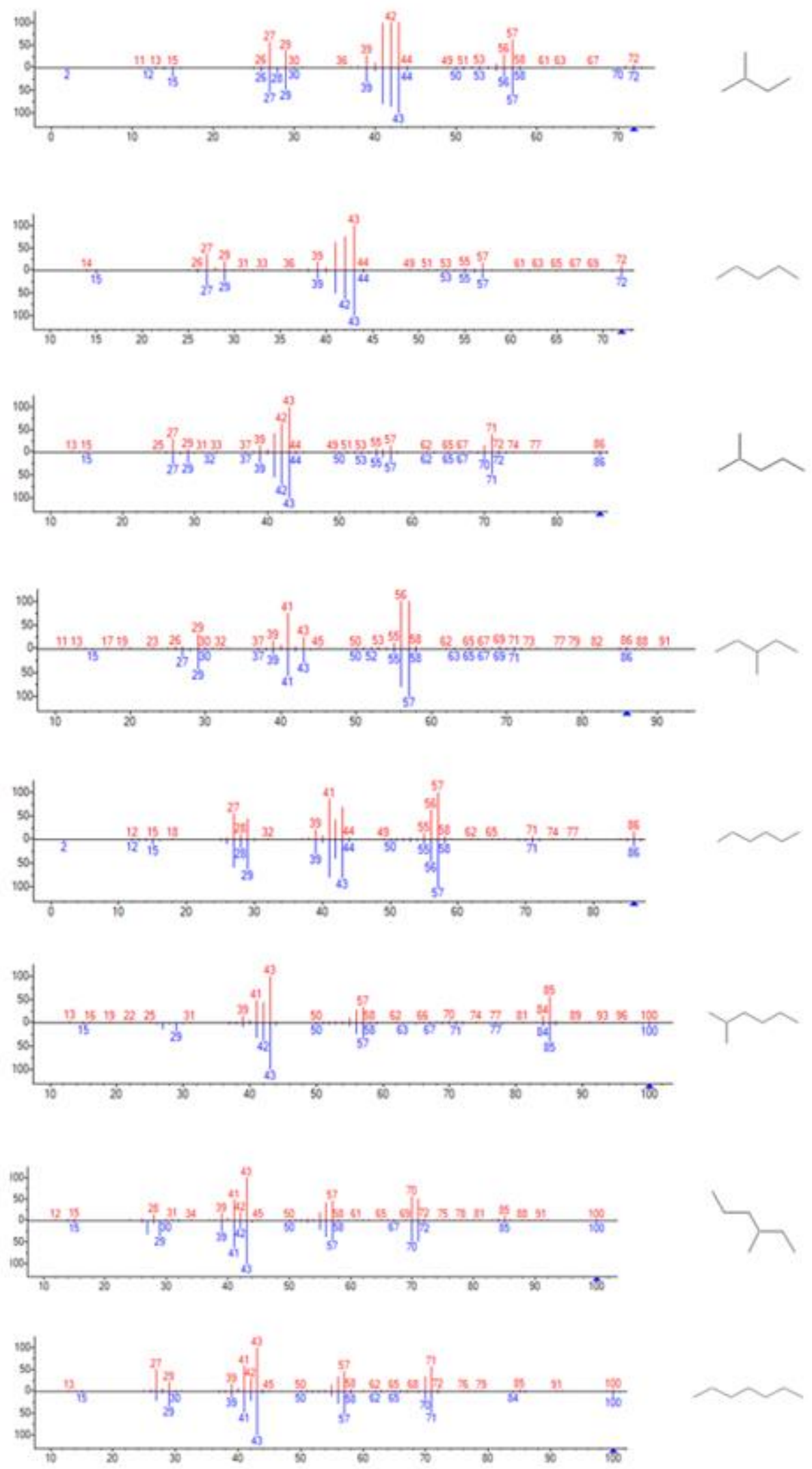

Figure S12. Comparison between experimental (red) and NIST data base (blue) mass-spectra used for identification of reaction products in GC spectra. 


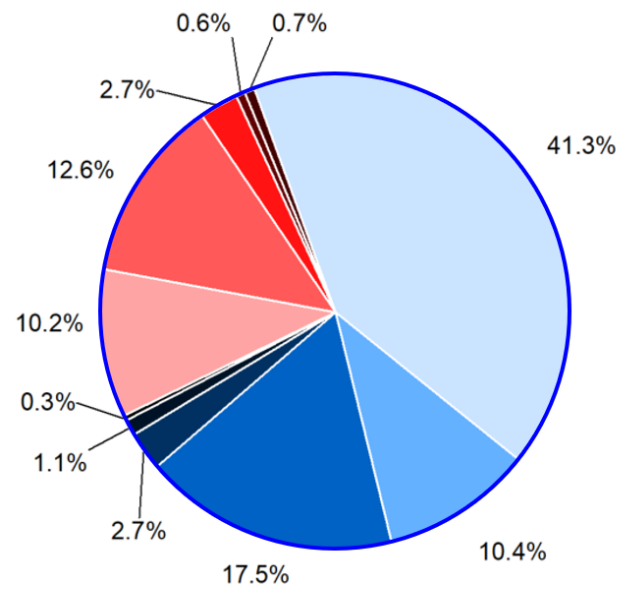

$\mathrm{Fe} / \mathrm{SiO}_{2}$

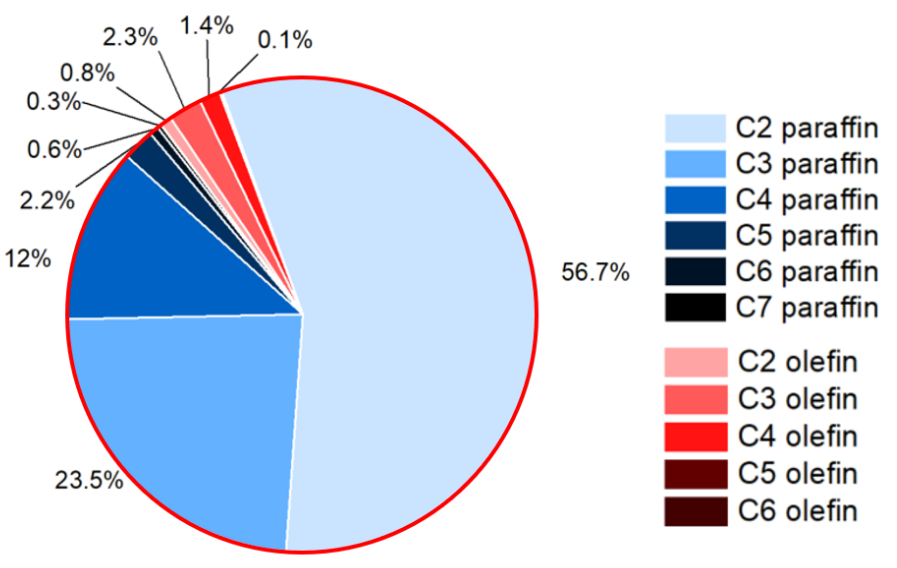

$\mathrm{Fe} / \mathrm{Al}_{2} \mathrm{O}_{3}$

Figure S13. Distribution of olefins and paraffins in the reaction products obtained over the 10 wt.\% $\mathrm{Fe} / \mathrm{SiO}_{2}$ and $\mathrm{Si} / \mathrm{Al}_{2} \mathrm{O}_{3}$ nanocrystalline powder catalysts.

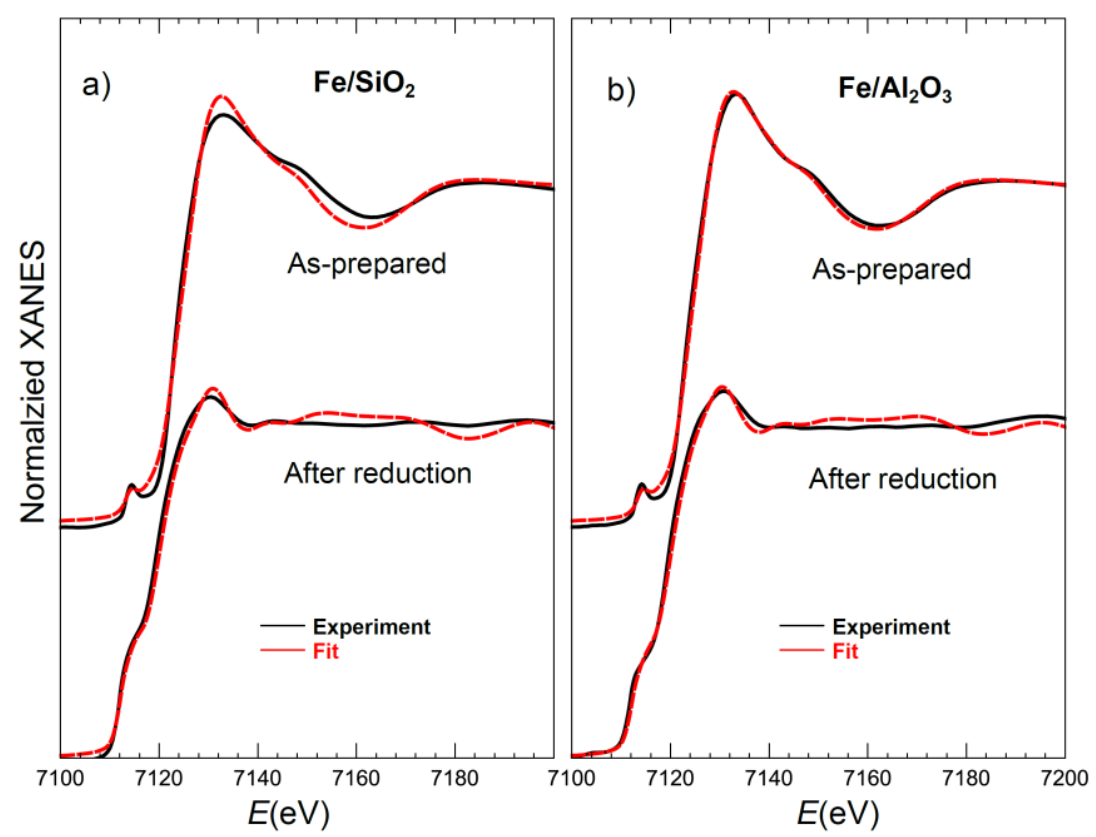

Figure S14. Representative linear combination fits of the Fe K-edge XANES spectra obtained on $\mathrm{SiO}_{2}$-supported (a) and $\mathrm{Al}_{2} \mathrm{O}_{3}$-supported (b) catalysts, "as-prepared" and after reduction in hydrogen. The spectra are offset for clarity. Fit R-factors for $\mathrm{Fe} / \mathrm{SiO}_{2}$ sample in as-prepared state and after reduction are $0.13 \%$ and $0.11 \%$. For $\mathrm{Fe} / \mathrm{Al}_{2} \mathrm{O}_{3}$ sample, corresponding $\mathrm{R}$-factors are $0.05 \%$ and $0.09 \%$. 
Table S1. Structure parameters (coordination numbers $N$, interatomic distances $\mathrm{R}$, disorder factors $\sigma^{2}$, third cumulant $\left.\mathrm{c}^{(3)}\right)$, obtained in fitting of experimental Fe K-edge EXAFS data. The error bar is given in parentheses.

\begin{tabular}{|c|c|c|c|c|c|c|c|c|c|}
\hline Sample & $\boldsymbol{N}_{\mathrm{Fe}-\mathrm{O}}$ & $\begin{array}{c}R_{F e-O} \\
(\AA))\end{array}$ & $\begin{array}{c}\sigma_{F e-o}^{2} \\
\left(\AA^{2}\right)\end{array}$ & $\begin{array}{c}c_{F e-o}^{(3)} \\
\left(\AA^{3}\right)\end{array}$ & $N_{F e-F e}$ & $\begin{array}{c}R_{F e-F e} \\
(\AA)\end{array}$ & $\begin{array}{c}\sigma_{F e-F e}^{2} \\
\left(\AA^{2}\right)\end{array}$ & $\begin{array}{r}\Delta \boldsymbol{E}_{0} \\
(\mathrm{eV})\end{array}$ & $\begin{array}{c}\text { Reliability } \\
\text { factor }\end{array}$ \\
\hline Fe foil & - & - & - & - & $\begin{array}{l}8 \\
6 \\
\end{array}$ & $\begin{array}{l}2.47(1) \\
2.86(1)\end{array}$ & $0.005(2)$ & $2(2)$ & $0.4 \%$ \\
\hline $\mathrm{FeOOH}$ & 6.1(1) & $2.004(8)$ & $0.0130(4)$ & $0.0014(2)$ & - & - & - & $5.5(5)$ & $0.1 \%$ \\
\hline $\begin{array}{c}\mathrm{Fe} / \mathrm{SiO}_{2} \\
\text { (as-prepared) }\end{array}$ & $5.4(3)$ & $2.02(2)$ & $0.010(1)$ & $0.0015(6)$ & - & - & - & $7(1)$ & $0.1 \%$ \\
\hline $\begin{array}{c}\mathrm{Fe} / \mathrm{SiO}_{2} \\
\text { (after reduction } \\
\text { in } \mathrm{H}_{2} \text { ) }\end{array}$ & $1.1(4)$ & $1.98(1)$ & $0.005(6)$ & - & $\begin{array}{l}5.0(7) \\
3.8(5)\end{array}$ & $\begin{array}{l}2.47(1) \\
2.86(1)\end{array}$ & 0.011(1) & $-1(2)$ & $1.0 \%$ \\
\hline $\begin{array}{c}\mathrm{Fe} / \mathrm{SiO}_{2} \\
\text { (after } \mathrm{CO}_{2}+\mathrm{H}_{2} \\
\text { reaction) }\end{array}$ & $1.1(1)$ & $1.94(1)$ & $0.002(2)$ & - & $\begin{array}{l}2.9(5) \\
2.2(3)\end{array}$ & $\begin{array}{l}2.47(1) \\
2.85(1)\end{array}$ & $0.006(1)$ & $-1(2)$ & $1.1 \%$ \\
\hline $\begin{array}{c}\mathrm{Fe} / \mathrm{Al}_{2} \mathrm{O}_{3} \\
\text { (as-prepared) }\end{array}$ & $4.9(1)$ & $2.01(1)$ & $0.011(1)$ & $0.0014(3)$ & - & - & - & $6.3(7)$ & $0.1 \%$ \\
\hline $\begin{array}{c}\mathrm{Fe} / \mathrm{Al}_{2} \mathrm{O}_{3} \\
\text { (after reduction } \\
\text { in } \mathrm{H}_{2} \text { ) }\end{array}$ & $1.5(1)$ & $2.00(1)$ & $0.006(2)$ & - & $\begin{array}{l}4.0(2) \\
3.0(2)\end{array}$ & $\begin{array}{l}2.47(1) \\
2.85(1)\end{array}$ & $0.007(1)$ & $-1.3(6)$ & $0.2 \%$ \\
\hline $\begin{array}{c}\mathrm{Fe} / \mathrm{Al}_{2} \mathrm{O}_{3} \\
\text { (after } \mathrm{CO}_{2}+\mathrm{H}_{2} \\
\text { reaction) }\end{array}$ & $0.7(4)$ & $2.02(2)$ & $0.01(1)$ & - & $\begin{array}{l}3.4(2) \\
2.5(1)\end{array}$ & $\begin{array}{l}2.48(2) \\
2.87(2)\end{array}$ & $0.007(1)$ & 1(3) & $2.8 \%$ \\
\hline
\end{tabular}

